Please share your stories about how Open Access to this article benefits you.

\title{
A new species of the allodapine bee genus Braunsapis from the Central African Republic (Hymenoptera: Apidae)
}

\author{
by Michael S. Engel
}

2013

This is the published version of the article, made available with the permission of the publisher. The original published version can be found at the link below.

Engel, Michael S. (2013). A new species of the allodapine bee genus Braunsapis from the Central African Republic (Hymenoptera: Apidae). Journal of Melittology 21:41646.

Published version: https://journals.ku.edu/index.php/melittology/ article/view/4609

Terms of Use: http://www2.ku.edu/ scholar/docs/license.shtml 


\title{
Journal of Melittology
}

Bee Biology, Ecology, Evolution, \& Systematics

The latest buzz in bee biology

No. 21, pp. $1-7$

29 October 2013

\section{A new species of the allodapine bee genus Braunsapis from the Central African Republic (Hymenoptera: Apidae)}

\author{
Michael S. Engel ${ }^{1}$
}

\begin{abstract}
A new species of the allodapine bee genus Braunsapis Michener (Allodapini: Allodapina) is described and figured from a series of females collected in the Central African Republic. Braunsapis maxschwarzi Engel, new species, is similar to B. paradoxa (Strand) from South Africa, both species sharing the concave dorsal surface of the sixth metasomal tergum and the peculiar bifid apical projection of the sixth metasomal sternum. The new species, however, can be distinguished by the more extensively developed yellow markings of the face, the yellow pronotal lobe, the more shoulder-like posterolateral margins of the sixth tergum [more similar in this regard to B. angolensis (Cockerell) and not greatly produced as in B. paradoxa], and the more erect and prominent dorsal setae of metasomal terga IV-VI, among other traits.
\end{abstract}

\section{INTRODUCTION}

The bee tribe Allodapini, although distributed widely in the Old World, is most diverse throughout Africa (Michener, 1975, 2007). The Asian fauna, excluding the Near East and Arabia, is solely comprised of species in the genus Braunsapis Michener, and the latter regions add to this a few species of the genera Exoneuridia Cockerell and Compsomelissa Alfken (Michener, 2007; Engel \& Dathe, 2011; Engel et al., in press). Australia has a rather robust fauna of nearly 100 species and representatives of five currently recognized genera (Michener, 2007). It is within the African continent, however, that the largest number of species is documented and where the known fauna is most likely to grow with intensive sampling across the equatorial regions. Over 125 species are presently known from Africa, including Madagascar, and these represent eight genera, depending on the classification adopted (Michener, 2007). The largest genus in Africa, and indeed the largest in the tribe, is Braunsapis, a group with varied biologies including frequent social behavior and even social parasitism (Michener, 1970, 1971, 2007; Reyes \& Michener, 1990; Aenmay et al., 2006).

\footnotetext{
${ }^{1}$ Division of Entomology, Natural History Museum, and Department of Ecology \& Evolutionary Biology, 1501 Crestline Drive - Suite 140, University of Kansas, Lawrence, Kansas 66045, USA (msengel@ku.edu).

Copyright $@$ M.S. Engel.

Creative Commons Attribution-NonCommercial-NoDerivs 3.0 Unported License (CC BY-NC-ND 3.0). ISSN 2325-4467
} 
Through the generosity of Maximilian Schwarz, a series of females of a new species of Braunsapis from the Central African Republic was brought to my attention (Fig. 1). The species was intended to be described by the late Stephen G. Reyes (19572006), but he did not have the opportunity to prepare a description or figures before he passed away. Herein I present the description of this species along with modified key couplets to aid its identification.

\section{MATERIAL AND METHODS}

Specimen repositories are denoted by the following abbreviations: MSCA, Maximilian Schwarz Collection, Ansfelden, Austria (ultimately to be deposited in the Oberösterreichisches Landesmuseum, Linz), and SEMC, Division of Entomology, University of Kansas Natural History Museum, Lawrence, Kansas, USA. Photomicrographs were prepared using a Canon 7D digital camera attached to an Infinity K-2 long-distance microscope lens. Measurements were taken with an ocular micrometer on an Olympus SZX-12 stereomicroscope and are of the holotype, with the range among paratypes in parentheses. The format for the description follows that of Engel \& Dathe (2011) and Engel et al. (in press), while the morphological terminology follows that of Engel (2001) and Michener (1975, 2007).

\section{SYSTEMATICS}

\section{Genus Braunsapis Michener}

Braunsapis maxschwarzi Engel, new species

ZooBank: urn:lsid:zoobank.org:act:DD996023-0FD8-43EA-9CC5-3601C64CECB2

(Figs. 1-7)

Diagnosis: The new species is most similar to Braunsapis paradoxa (Strand) from South Africa, both species having a distinctive bifid medioapical projection on the sixth metasomal sternum that extends beyond the apex of tergum VI in dorsal view (e.g., Figs. 6, 7). The much more northerly and slightly smaller B. maxschwarzi n. sp. differs by the extensively developed yellow clypeal markings (Figs. 1, 2) (greatly reduced to absent in B. paradoxa), the the yellow pronotal lobe (Fig. 1) (dark brown to black in B. paradoxa), the largely yellow median axillary sclerite (dark brown in B. paradoxa), the clypeoantennal distance distinctly less than the diameter of the antennal torulus (Fig. 2) (about equal to the diameter of the antennal torulus in B. paradoxa), the easily visible dorsal setae of the metasomal terga (scarcely evident in B. paradoxa), the less developed lateral shoulders of the sixth tergum (Fig. 7) (strongly elevated and produced apically in B. paradoxa), and the shorter and more blunt bifid projection of the sixth sternum (Fig. 7) (bifid projections longer and more acute in B. paradoxa).

Description: : : Total length $6.00 \mathrm{~mm}(5.25-6.25 \mathrm{~mm})$; forewing length $4.06 \mathrm{~mm}$ (3.81-4.44 mm); head slightly broader than long, length $1.53 \mathrm{~mm}(1.45-1.63 \mathrm{~mm})$, width $1.61 \mathrm{~mm}(1.53-1.69 \mathrm{~mm})$; compound eyes with inner margins relatively straight, converging below (Fig. 2), upper interorbital distance $1.04 \mathrm{~mm}(0.94-1.10 \mathrm{~mm})$, lower interorbital distance $0.78 \mathrm{~mm}(0.71-0.78 \mathrm{~mm})$. Mandible tridentate, median tooth largest; malar space much shorter than one-third basal mandibular width, anteriorly about two-thirds as long as apical scape width, posteriorly about three-quarters (or slightly more) as long as apical scape width. Clypeus flat, not protuberant, with upper border very weakly concave, nearly straight (Fig. 2); lower clypeoocular distance about two- 


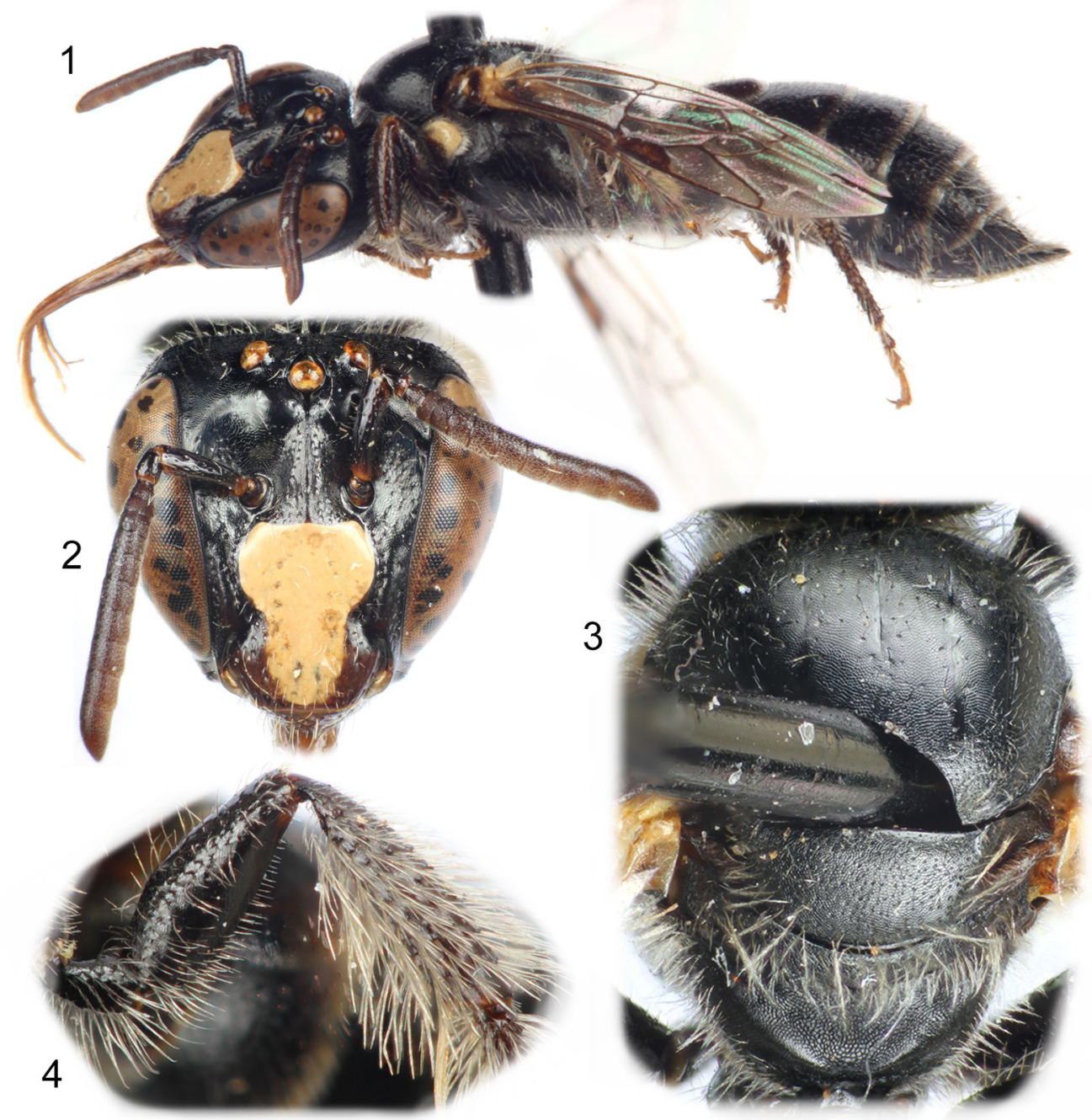

Figures 1-4. Photomicrographs of female of Braunsapis maxschwarzi, new species, from the Central African Republic. 1. Lateral habitus. 2. Facial view. 3. Dorsal detail of mesosoma. 4. Detail of metafemur and metatibia.

thirds scape width, upper clypeocular distance about twice scape width; clypeoantennal distance less than diameter of antennal torulus. Scape short, extending to just above level of lower margin of median ocellus, about 4-4.5 times as long as apically broad; first flagellomere very slightly broader than long, second about twice as broad as long, following flagellomeres progressively longer so that penultimate flagellomere is about as long as broad. Vertex straight and slightly above upper tangent of compound eyes in frontal view (Fig. 2). Genal area medially about as wide as compound eye in lateral view. Forewing venation generally typical for genus; pterostigma shorter than costal border of marginal cell, about as long as distance from apex of cell to wing tip; marginal cell apex separated from wing margin by about vein width; second submarginal cell less than half length of first submarginal cell; 1rs-m near 1m-cu. Legs 


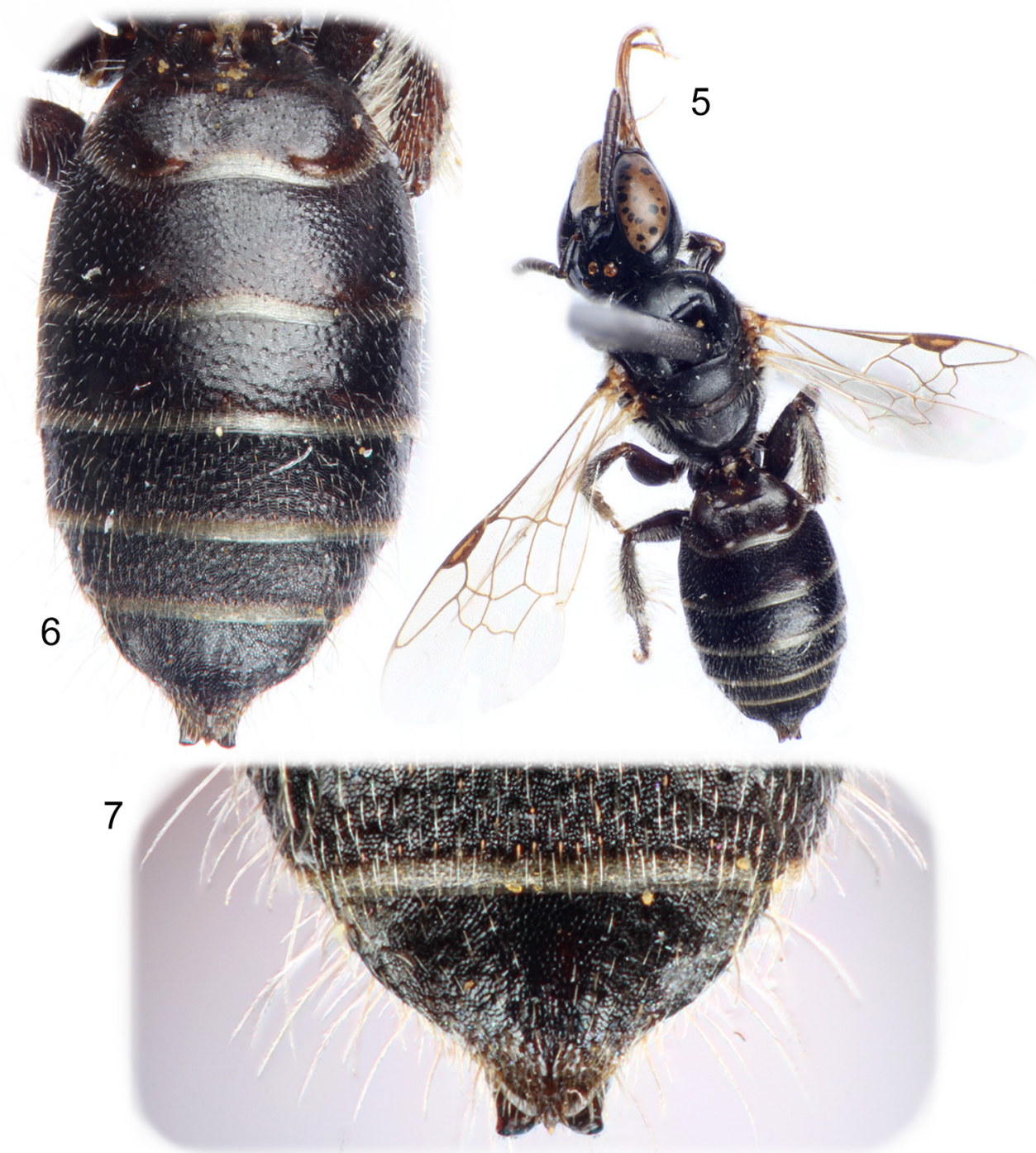

Figures 5-7. Photomicrographs of female of Braunsapis maxschwarzi, new species, from the Central African Republic. 5. Dorsal habitus. 6. Dorsal detail of metasomal terga. 7. Detail of apical metasomal segments (apical portion of tergum $\mathrm{V}$ and entirety of tergum VI, with bifid projection of sternum VI visibly projecting from beneath).

unmodified; metabasitibial plate not defined (not margined by carina), represented solely by small glabrous area. Metasoma typical for genus except sixth tergum with dorsal surface gently concave, lateral shoulders only weakly elevated and not greatly produced apically (strongly produced apically in B. paradoxa: vide figure 160 in Michener, 1975), lateral margins of sixth tergum gently convex at apicolateral corners (Fig. 7), thereafter tapering gently from angle to broadly rounded medioapical margin [in this respect somewhat more similar to B. angolensis (Cockerell), a species which also has a concave dorsal surface on the sixth tergum], medioapical margin weakly and shallowly emarginate; sterna generally unmodified except sixth sternum medioapically produced, with bifid apex that extends beyond apex of sixth tergum (Figs. 5-7), 
bifid apices somewhat blunt (Fig. 7) (more acutely pointed, with deeper emargination in B. paradoxa).

Labrum with coarse punctures separated by much less than a puncture width, integument otherwise smooth and shining; clypeus shining, faintly and finely imbricate, with shallow, somewhat inconspicuous punctures separated by a puncture width or frequently less; remainder of face with irregular finely and faintly imbricate areas and areas of small, faint punctures often separated by less than a puncture width (e.g., near medial line of face); vertex more distinctly imbricate and largely impunctate, areas very sparsely with a few small, shallow punctures; gena as on vertex; postgena imbricate and impunctate. Mesoscutum imbricate, with small, shallow punctures very sparsely scattered (Fig. 3), such punctures a bit more numerous along lateral and posterior borders; tegula finely and faintly imbricate, impunctate; mesoscutellar integument similar to that of mesoscutum, punctuation similar to that of mesoscutum although more numerous, separated by 1-2 times a puncture width except more widely spaced posteriorly; metanotum coarsely imbricate; pleural punctation similar to that of mesoscutum except punctures separated by 1.5-3 times a puncture width, punctures fainter ventrally and posteriorly on mesepisternum; propodeum very coarsely imbricate (so much so that surface could well be described as finely reticulate) (Fig. 3). Legs finely imbricate except almost smooth on apical ventral surface of metafemur. Metasomal terga and sterna imbricate, with scattered shallow, coarse, and faint punctures except apical margins impunctate (Fig. 6).

Integument mostly black. Mandible dark brown. Labiomaxillary complex brown. Labrum brown. Clypeus largely yellow except for dark brown apicolateral areas; yellow T-shaped marking strongly developed, occupying entire upper portion of clypeus (at and above tangent of anterior tentorial pits) and comprising wide mediolongitudinal band across lower portion of clypeus (Figs. 1, 2); remainder of head black. Antenna dark brown except slightly lighter on ventral base of scape. Mesosoma black except pronotal lobe yellow (Fig. 1), tegula light brown and translucent, outer margin almost colorless (Fig. 5). Legs dark brown expect apical tarsomeres lighter, almost yellowish brown on apical pro- and mesotarsomeres. Wings hyaline; wing base with costal and radial sclerite brown, median sclerite largely yellow except brown proximally, remaining axillaries yellow; veins light brown except $\mathrm{Sc}+\mathrm{R}$ and borders of pterostigma darker. Metasoma black except apical margins narrowly semitranslucent (Fig. 6).

Pubescence sparse (as is typical across the genus), whitish translucent or tinged lightly fuscous on tarsi, not forming tergal pale bands; metatrochanter with long, simple setae ventrally; metafemur with large bare area ventrally in apical half, otherwise with scattered, short to long, largely simple setae; metatibia with numerous elongate setae, setae with a few branches or simple (Fig. 4); dorsal metasomal setae sparse but prominent, with tapered apices, distinctly noticeable in profile.

ô: Unknown.

Holotype: + , Republique Centrafricaine, leg. Dollfuss / Kembé [Basse-Kotto Prefecture], 4.29 N, 21.53 E, 1985-07-27 [27 July 1985] (MSCA).

Paratypes: 19 , Republique Centrafricaine, leg. Dollfuss / Kembé [Basse-Kotto Prefecture], 4.29 N, 21.53 E, 1985-07-12 [12 July 1985] (SEMC); 2우, Republique Centrafricaine, leg. Dollfuss / Kembé [Basse-Kotto Prefecture], 4.29 N, 21.53 E, 1985-07-12 [12 July 1985] (MSCA); 1ㅇ, Republique Centrafricaine, leg. Dollfuss / Kembé [BasseKotto Prefecture], 4.29 N, 21.53 E, 1985-08-07 [7 August 1985] (MSCA); 1ㅇ, Republique Centrafricaine, leg. Dollfuss / Kembé [Basse-Kotto Prefecture], 4.29 N, 21.53 E, 198508-08 [8 August 1985] (MSCA); 1ㅇ, Republique Centrafricaine, leg. Dollfuss / Kembé 
[Basse-Kotto Prefecture], 4.29 N, 21.53 E, 1985-08-08 [8 August 1985] (SEMC); 1ㅇ, Republique Centrafricaine, leg. Dollfuss / Kembé [Basse-Kotto Prefecture], 4.29 N, 21.53 E, 1985-08-11 [11 August 1985] (MSCA); 2 우, Republique Centrafricaine, leg. Dollfuss / Kembé [Basse-Kotto Prefecture], 4.29 N, 21.53 E, 1985-08-11 [11 August 1985] (SEMC); 1오 Republique Centrafricaine, leg. Dollfuss / Kembé [Basse-Kotto Prefecture], 4.29 N, 21.53 E, 1985-08-17 [17 August 1985] (MSCA).

EтYмоlogy: The specific epithet is a patronym honoring Dr. Maximilian Schwarz who provided the material reported herein and who has made numerous important contributions to the systematics of bees for more than 40 years.

Comments: Specimens of various African Braunsapis were studied in the collection of the Division of Entomology, University of Kansas Natural History Museum. In particular, females (and males, although a male remains to be captured for B. maxschwarzi) for $B$. angolensis and B. paradoxa were compared with the above type series.

In Michener's (1975) key to females of African species of Braunsapis, the new species will run to B. paradoxa. The following modified couplets will permit inclusion of this species into those dichotomous couplets:

5(4). Sixth sternum with a bifid medioapical projection extending beyond apical tergum $5 a$

-. Sixth sternum of the usual simple form (Angola, Burundi, Rwanda, Kenya) ...... B. angolensis (Cockerell)

5a(5). Yellow T-shaped marking on clypeus reduced to median stem, spots, weak line along base of clypeus, or absent; clypeoantennal distance about equal to diameter of antennal torulus; pronotal lobe black; median axillary sclerite brownish black; dorsal setae of metasomal terga IV-VI very short and sparse, scarcely noticeable in profile; sixth tergum with lateral shoulders strongly elevated and produced posteriorly, apical margin between prominent lateral shoulders concave or straight to margin of bifid sternal projection giving apex of metasoma a quadrate or even quadridentate appearance (South Africa) ....

B. paradoxa (Strand)

-. Yellow T-shaped marking on clypeus strongly developed, occupying entire upper portion of clypeus (at and above tangent of anterior tentorial pits), and comprising wide mediolongitudinal band across lower portion of clypeus (Figs. 1, 2); clypeoantennal distance distinctly less than diameter of antennal torulus (Fig. 2); pronotal lobe yellow (Fig. 1); median axillary sclerite largely yellow, with some brown proximally; dorsal setae of metasomal terga IV-VI erect and prominent, easily visible in profile; sixth tergum with lateral shoulders only weakly elevated and not so greatly produced, tapering gently from angle of shoulders to margin of bifid sternal projection (Figs. 6, 7) (Central African Republic) .................................................... B. maxschwarzi Engel, n. sp.

\section{ACKNOWLEDGEMENTS}

It is with great thanks that I acknowledge Maximilian Schwarz for providing the specimens reported herein, encouraging their study, and permitting a subset of the paratypes to be retained for the University of Kansas. I am further grateful to two anonymous reviewers and Charles D. Michener for comments on the manuscript, and to Victor H. Gonzalez for assistance with photomicrography. Partial support was provided by the Engel Illustration Fund of the University of Kansas College of Liberal Arts \& Sciences. This is a contribution of the Division of Entomology, University of Kansas Natural History Museum. 


\section{REFERENCES}

Aenmay, T.K., S.M. Tierney, N. Pillay, \& M.P. Schwarz. 2006. Nesting biology of an African allodapine bee Braunsapis vitrea: Female biased sex allocation in the absence of worker-like behavioural castes. Ethology, Ecology, and Evolution 18(3): 205-220.

Engel, M.S. 2001. A monograph of the Baltic amber bees and evolution of the Apoidea (Hymenoptera). Bulletin of the American Museum of Natural History 259: 1-192.

Engel, M.S., \& H.H. Dathe. 2011. Order Hymenoptera, family Apidae: Tribe Allodapini, genus Braunsapis. Arthropod Fauna of the UAE [United Arab Emirates] 4: 630-635.

Engel, M.S., A.S. Alqarni, M.A. Hannan, I.A. Hinojosa-Díaz, \& C.D. Michener. In press. Allodapine bees in the Arabian Peninsula (Hymenoptera: Apidae): A new species of Braunsapis from the Sarawat Mountains, with an overview of the Arabian fauna. American Museum Novitates

Michener, C.D. 1970. Nest sites of stem and twig inhabiting African bees (Hymenoptera: Apoidea). Journal of the Entomological Society of Southern Africa 33(1): 1-22.

Michener, C.D. 1971. Biologies of African allodapine bees. Bulletin of the American Museum of Natural History 145(3): 219-305.

Michener, C.D. 1975. A taxonomic study of African allodapine bees (Hymenoptera, Anthophoridae, Ceratinini). Bulletin of the American Museum of Natural History 155(2): 67-240.

Michener, C.D. 2007. The Bees of the World [2nd Edition]. Johns Hopkins University Press; Baltimore, $\mathrm{MD} ; \mathrm{xvi}+[\mathrm{i}]+953$ pp., +20 pls.

Reyes, S.G., \& C.D. Michener. 1990. Observations on a parasitic allodapine bee and its hosts in Java and Malaysia (Hymenoptera Anthophoridae Allodapine [sic]). Tropical Zoology 3(2): 139-149.

ZooBank: urn:lsid:zoobank.org:pub:6E4B63ED-35B2-4CD9-A301-A96B22D41C5A 


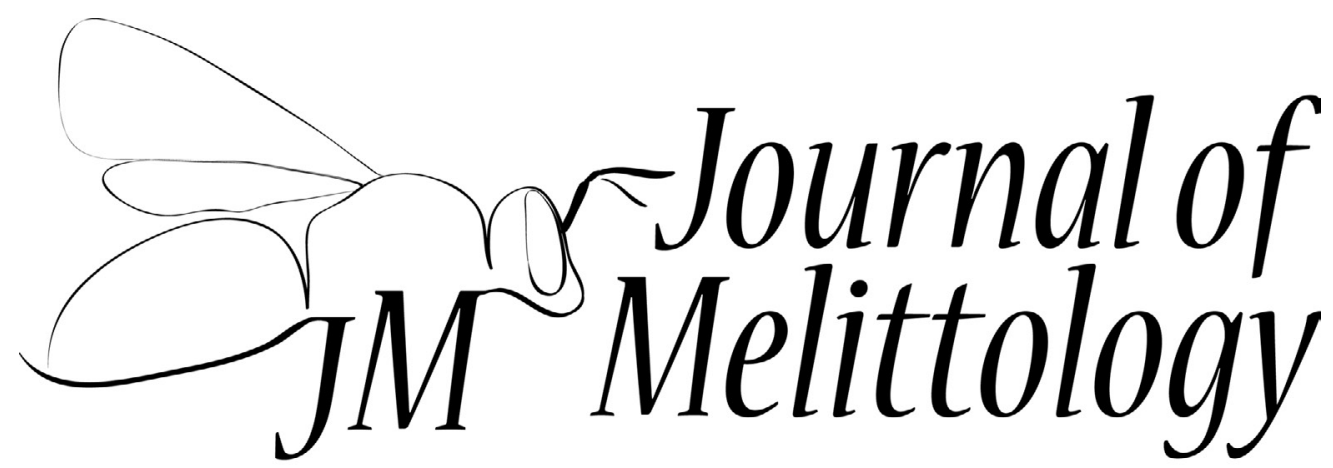

A Journal of Bee Biology, Ecology, Evolution, \& Systematics

The Journal of Melittology is an international, open access journal that seeks to rapidly disseminate the results of research conducted on bees (Apoidea: Anthophila) in their broadest sense. Our mission is to promote the understanding and conservation of wild and managed bees and to facilitate communication and collaboration among researchers and the public worldwide. The Journal covers all aspects of bee research including but not limited to: anatomy, behavioral ecology, biodiversity, biogeography, chemical ecology, comparative morphology, conservation, cultural aspects, cytogenetics, ecology, ethnobiology, history, identification (keys), invasion ecology, management, melittopalynology, molecular ecology, neurobiology, occurrence data, paleontology, parasitism, phenology, phylogeny, physiology, pollination biology, sociobiology, systematics, and taxonomy.

The Journal of Melittology was established at the University of Kansas through the efforts of Michael S. Engel, Victor H. Gonzalez, Ismael A. Hinojosa-Díaz, and Charles D. Michener in 2013 and each article is published as its own number, with issues appearing online as soon as they are ready. Papers are composed using Microsoft Word ${ }^{\circledR}$ and Adobe InDesign ${ }^{\circledR}$ in Lawrence, Kansas, USA.

\section{Editor-in-Chief \\ Michael S. Engel \\ University of Kansas}

\section{Assistant Editors}

Victor H. Gonzalez

Southwestern Oklahoma State University
Charles D. Michener

University of Kansas

Journal of Melittology is registered in ZooBank (www.zoobank.org), archived at the University of Kansas and in Portico (www.portico.org), and printed on demand by Southwestern Oklahoma State University Press. 